\title{
Relato
}

Ana Carolina Rocha Carneiro'

\section{Infância e diversidade cultural: uma reflexão sobre o filme "Babies"}

RESUMO: $O$ presente texto tem como objetivo promover uma reflexão sobre os aspectos culturais no desenvolvimento da infância caracterizado no filme "Babies" (20 I 0), no qual é acompanhado o crescimento de quatro bebês de nacionalidades diferentes até completarem um ano de vida. A reflexão vale-se das concepções de infância de acordo com Campos (2008), Carvalho (20 I0), Christensen (2005), Corsaro (2009), Javeau (2005), Kohan (2003) e Sarmento (2004), as quais foram relacionadas aos aspectos do filme. Este texto está, ainda, constituído por dois eixos: cada um corresponde aos bebês representados em um espaço rural - Bayar na Mongólia e Ponijao em Namíbia -; e em um espaço urbano - Hattie nos Estados Unidos e Mari no Japão. O filme é atemporal e é um retrato da infância de múltiplas nacionalidades, no qual a diversidade cultural faz parte da narrativa, demonstrando estímulos e hábitos de infâncias tão comuns, e ao mesmo tempo, tão diferentes. Por meio dele temos à disposição uma exemplificação de aspectos teóricos vistos na prática, além de nos remeter a uma experiência estética. "Babies" dá uma aula de observação de crianças e revela como devem ser levados em conta os aspectos culturais e todo contexto que envolve esses indivíduos quando são considerados sujeitos de uma pesquisa.

Palavras-chave: Infância. Diversidade cultural. Filme. Babies.

\section{Childhood and cultural diversity: a reflection on the movie "Babies"}

ABSTRACT: The following text aims to promote a reflection on the cultural aspects of childhood development featured in the movie "Babies" (20 I 0), in which the growth of four babies from different nationalities until they complete one year of life is accompanied. The reflection counts on the childhood conceptions according to Campos (2008), Carvalho (20 I0), Christensen (2005), Corsaro (2009), Javeau (2005), Kohan (2003) and Sarmento (2004), which were related to the aspects of the movie. This text is also constituted of two axis: each one corresponds to babies represented in a rural area - Bayar in Mongolia and Ponijao in Namibia -; and in an urban space - Hattie in the United States and Mari in Japan. The movie is timeless, and it is a childhood portrait of multiple nationalities, in which the cultural diversity is part of the narrative, showing so common childhood stimulations and habits, and yet, so different. Through it an exemplification of theoretical aspects seen in practice is available, as well as it remits us to an esthetics experience. "Babies" gives a lesson of children observation and reveals how the cultural aspects and the context of these individuals should be taken into account when they are considered research subjects.

Key words: Childhood. Cultural diversity. Movie. Babies.

I Mestranda em Educação no Programa de Pós Graduação em Educação (PPGE) da Universidade do Vale do Itajaí (Univali), Linha de Pesquisa Cultura, Tecnologia e Aprendizagem. Bolsista CAPES. Graduada em Comunicação Social com Habilitação em Jornalismo pela Universidade do Vale do Itajaí (Univali). Itajaí, Santa Catarina, Brasil. 
presente texto relata uma experiência que teve como objeto de estudo o filme de
produção francesa "Babies" (2010), um documentário não narrado. Através do relato, o objetivo é promover uma reflexão sobre os aspectos culturais no desenvolvimento da infância caracterizado no filme, que retrata o crescimento de quatro bebês de nacionalidades diferentes até completarem um ano de vida.

Como pano de fundo para a reflexão temos a infância, retratada desde a gestação - se é que nela também podemos caracterizar a infância, como nos lembra Javeau (2005), até o primeiro ano de cada um dos personagens principais: Bayar, Ponijao, Hattie e Mari, que mesmo em culturas diferentes, têm um ponto em comum: são retratados "como um ser em transformação" (CARVALHO, 2010, p. 121). Esta transformação pode ser vista no desenvolver das suas falas, da alimentação, no andar, entre outros aspectos.

A reflexão aqui proposta vale-se das concepções de infância de acordo com Campos (2008), Carvalho (2010), Christensen (2005), Corsaro (2009), Javeau (2005), Kohan (2003) e Sarmento (2004).

Deste modo, o relato segue dividido em três sessões. Na primeira, é descrito o objeto de estudo e o contexto da experiência com o filme. Em seguida, é apresentado um panorama sobre a infância, tema que norteia a reflexão. Por fim, para uma melhor relação entre teoria e prática, os meios de socialização dos personagens presentes no filme foram agrupados de acordo com a localização dos bebês - que já podem ter suas diferenças percebidas desde o minuto inicial do filme: espaços onde a cultura existente parece manter características rurais e espaços onde a cultura urbana fica em evidência. É neste sentido que, dividido em dois eixos, o texto finaliza apresentando uma caracterização de cada personagem e seus modos de vida. 


\section{Aexperiência}

Babies2 - filme selecionado para este relato - tem como título original "Bébé(s)", e foi produzido em 2010, na França, sob a forma de um documentário não narrado. Ele possui cerca de 80 minutos de duração, foi dirigido por Thomas Balmès e coescrito por Alain Chabat. É um filme atemporal, que suscita diversas reflexões por abordar culturas diversas. Seus personagens são verídicos e em grande parte do filme, podemos perceber que as câmeras estavam ocultas, com o intuito de não causar nenhuma interferência nas imagens coletadas do dia a dia das crianças (característica difundida no meio acadêmico, para a pesquisa).

O retrato da infância através das câmeras pode suscitar elementos imprescindíveis para pesquisas com estes sujeitos, porque proporciona um registro real e fiel ao cotidiano dos mesmos, o que incide por consequência, em análises complexas. Este método oferece ainda a oportunidade de comparação entre diferentes realidades, sob os mesmos aspectos, como é o caso do filme aqui indicado.

O olhar sobre o cinema, ou sobre a infância representada na tela, nos
instiga a aprender sobre nós mesmos frente à infância, tomando
seriamente outras culturas, outros olhares, como interlocutores que
nos tocam não apenas ao pensamento racional, mas aquilo que
sentimos e experimentamos. Podemos, então, nos perguntar: o que
dá para pensar? A maior contribuição não é a constatação do que
pretendeu o autor ou diretor sobre a infância em sua obra, mas o que,
a partir das nossas interpretações frente a esta, nos interroga, nos
desestabiliza, nos incita na busca ativa para novas e profundas relações
e interpretações (Lima; Nazário; Schmitt, 20 I3, p. 4).

Como sugerem os autores, refletir sobre a infância sob esta forma de arte não requer somente um olhar crítico, mas também nos remete a trabalhar com as emoções, influenciando as interpretações daquilo que se vê com aspectos de nossas histórias de vida, conhecimento de mundo, ideologias, entre outros. O filme selecionado nos proporciona inclusive, uma experiência estética.

Ainfância

O conceito de infância adotado para esta reflexão segue a linha na qual, "a ideia de infância é uma ideia moderna" (SARMENTO, 2004, p. 3), tendo como exemplo as sociedades europeias, as quais, “durante a época medieval, não havia um sentimento ou consciência de 'infância' (...), ela estava limitada a esse período relativamente curto, mais frágil da vida, em que uma pessoa ainda não pode

Ver http://mwn.focusfeatures. com/babies 
satisfazer por si mesma suas necessidades básicas” (KOHAN, 2003, p. 63).

Consideradas, posteriormente, "adultos em miniatura" (KOHAN, 2003, p. 63), as crianças logo passavam de bebês a homens e mulheres, assim que deixassem de ser tão pequenas. Mas, "a partir do séc. XVII se produz uma mudança considerável: começa a se desenvolver um sentimento novo com relação à infância. A criança passa a ser o centro das atenções dentro da instituição familiar" (KOHAN, 2003, p. 66). Notamos isso no filme, quando as atividades dos pais passam a sofrer algum tipo de modificação com a chegada da criança, como o caso do bebê da Mongólia, que fica amarrado enquanto sua mãe realiza suas atividades, ou a bebê dos Estados Unidos, que é colocada em uma cadeirinha enquanto seu pai realiza serviços domésticos.

Adquirir a fala ou passar a frequentar a escola, assim como para alguns autores o início do trabalho, são alguns dos aspectos abordados em pesquisas utilizados para marcar um fim para o período da infância. Parte-se do pressuposto de que a partir do momento em que se chega a tais ideais, a independência é alcançada, e assim, percebe-se que "a criança adquire um novo espaço dentro e fora da instituição familiar" (KOHAN, 2003, p. 66).

“Babies” segue o que Christensen e James (2005) parafraseiam Solberg (1996, p. 63), sobre a pesquisa com crianças, quando ressaltam que "deve-se estar aberto à investigação empírica, para explorar o significado da idade e do estatuto dentro dos diferentes contextos e situações, para explorar 'o que fazem', em vez do que 'são”' (p. XV). O filme parece ter justamente esta intenção: investigar o que estes quatro bebês - como sujeitos - fazem e aprendem em diversas situações, acompanhados ou não, no seu dia a dia.

Cruz corrobora a ideia, quando critica que a criança não pode ser ouvida e/ou observada somente dentro da escola:

$$
\begin{aligned}
& \text { (...) as mesmas crianças se comportavam de forma muito diferente na } \\
& \text { escola, na família e em outras situações, como brincando nas ruas ou } \\
& \text { ajudando os pais no trabalho. Será que não deveríamos também } \\
& \text { procurar ouvir as crianças nos diferentes contextos em que elas } \\
& \text { circulam? Estaremos mesmo captando a cultura infantil justamente } \\
& \text { onde ela costuma ser mais reprimida, isto é, na escola? (2008, p. } 4 \text { I). }
\end{aligned}
$$

Nossos personagens principais - Bayar, Ponijao, Hattie e Mari - apesar de estarem passando pela mesma etapa de vida, demonstram muitos aspectos diferentes uns dos outros, caracterizados por suas culturas. Desta forma, como os outros grupos sociais, as crianças arranjam suas existências cotidianas com os meios que podem. Esses meios lhes são dados pelos dispositivos de socialização que lhes são impostos ou propostos (Javeau, 2005, p. 386).

O autor descreve ainda que 
(...) construiu-se um objeto abstrato, a "criança", destinado a passar por níveis diversos e sucessivos na aquisição de competências, cada um deles constituindo uma etapa na fabricação da personalidade dos indivíduos. Em certos textos, essas etapas adquirem uma coloração normativa, pouco se importando com a variedade dos contextos efetivos nos quais indivíduos concretos são chamados a se "desenvolver" (p. 382).

Seja junto da natureza, dos animais, dos próprios pais ou objetos, este contexto pode ser visualizado no filme de maneira clara. O desenvolvimento da personalidade desses indivíduos também se acentua a cada situação desafiadora pela qual eles passam. Os quatro bebês brincam em suas diversidades culturais e são felizes, saudáveis. A infância, apesar de em processo de mudança não só cultural, como também social, continua a se transformar.

A cultura de pares é reforçada por Sarmento, quando diz que ela

permite às crianças apropriar, reinventar e reproduzir o mundo que as rodeia. A convivência com os seus pares, através da realização de actividades e rotinas, permite-lhes exorcizar medos, representar fantasias e cenas do quotidiano, que assim funcionam como terapias para lidar com experiências negativas. Esta partilha de tempos, acções, representações e emoções é necessária para um mais perfeito entendimento do mundo e faz parte do processo de crescimento (2004, p. 14).

Castelli e Mota reforçam a ideia de que em seus grupos sociais e com seus pares, as crianças, através de manifestações de linguagem como olhares, mordidas, risadas e choros, vão criando, recriando e deixando suas marcas no mundo. Elas vão se percebendo enquanto capazes, ativas, visto que encontram incontáveis maneiras de ver e fazer as coisas, diferentemente de nós, adultos, que muito ainda estamos presos às formas estereotipadas e fixas de viver e pensar (2013, p. 2).

Junto a isso, cada bebê presente no filme demonstra começar a desenvolver sua identidade e personalidade, conforme o mundo exterior a que estão sendo expostas e se relacionam. Sarmento explica que "esta identidade das crianças é também a identidade cultural, isto é a capacidade das crianças constituírem culturas não redutíveis totalmente às culturas dos adultos” (2004, p.11).

Portanto, seu papel como nova geração na história é importante:

As culturas da infância exprimem a cultura societal em que se inserem, mas fazem-no de modo distinto das culturas adultas, ao mesmo tempo que veiculam formas especificamente infantis de inteligibilidade, representação e simbolização do mundo. As crianças portuguesas pertencem à cultura (heterogénea e complexa) portuguesa mas contribuem activamente para a construção permanente das culturas da infância. Nesse sentido há uma "universalidade" das culturas infantis que ultrapassa consideravelmente os limites da inserção cultural local de cada criança. Isso decorre do facto das crianças construírem nas suas interacções "ordens sociais instituintes" (Ferreira, 2002), que 
regem as relações de conflito e de cooperação, e que actualizam, de modo próprio, as posições sociais, de gênero, de etnia e de cultura que cada criança integra (Sarmento, 2004, p. 12).

Estes aspectos também sofrem impacto dos espaços nos quais estes bebês se desenvolvem, o que de certa foram agrupa e estabelece diferenças entre os personagens do filme, como descrito a seguir.

OESPAÇO CULTURAL RURAL

Bayar, o bebê amigo do galo

Nascido em Bayanchandmani, na Mongólia, Bayar é o apelido de Bayarjargal. Ele mora com sua mãe, pai e um irmão mais velho chamado Delgerjargal. Nômades, sua casa é pequena, em meio a um campo, mas possui antena parabólica. A todo momento, seu irmão aproveita o distanciamento dos pais para implicá-lo. Costuma ficar amarrado dentro de casa, pela mão ou pelo tronco. Animais o rondam quando está tomando banho.

Em sua participação no filme, além dos aspectos culturais, é evidente "a relação de poder inerentes entre crianças e adultos, que não podem ser ignoradas" (CHRISTENSEN; JAMES, 2005, p. XVIII). O bebê utiliza o choro para chamar a atenção da mãe quando o irmão o incomoda. Não só como uma forma de se comunicar, Bayar chora quase como para que se "fazer de vítima" e ter o irmão punido. Como lembra Corsaro (2009), é como se as crianças quisessem que isso acontecesse. Elas querem criar e compartilhar emocionalmente o poder e controle que os adultos têm sobre elas. Este é um exemplo de como se deve pensar no que as crianças “fazem”, ao invés do que elas "são", como já comentado por CHRISTENSEN EJAMES (2005).

Ponijao, o bebê amigo do cachorro

Nascido em Opuwo, em Namíbia, Ponijao mora com seus pais e oito irmãos e irmãs mais velhas. Sua família faz parte da Tribo Himba, e vive em uma pequena vila com outras famílias. Em comunidade, sobrevivem da natureza, sem recursos tecnológicos. Ponijao bebe água de um riacho, lambe os animais, come areia, brinca e engatinha sobre pedras, tudo isso sem calçados ou vestimentas "adequadas".

Aqui se notam aspectos da pesquisa científica em que (...) se trata antes de tudo de por em 
evidência as significações que as crianças atribuem aos diversos componentes dos estilos de vida que levam (Javeau, 2005, p. 385).

Neste caso, Ponijao não deixa de se desenvolver por estar em condições diferentes das nossas. Seus processos de socialização apesar de diferentes são os mesmos. Deve-se

(...) levar em consideração, no que diz respeito às crianças de diversos meios (e não só às das sociedades desenvolvidas), as importantes modificações advindas em torno delas, entre as quais a mais imediata que lhes possa passar pela cabeça é a família (Javeau, 2005, p. 387).

O filme é muito rico neste sentido, quando demonstra em cada personagem seus modos de socialização e vivências especificas de suas culturas.

\section{OESPAÇO CULTURAL URBANO}

Hattie, a bebê amiga do gato

Nascida em São Francisco, na Califórnia, Hattie é filha de pais que "prezam pela ecologia". Branca, de olhos azuis, fica na cadeirinha enquanto o pai cozinha, e é estimulada a ler livros pela mãe. Engatinha sobre o assoalho do apartamento e tenta fugir do grupo de atividades entre pais e filhos quando consegue andar. Aprende a falar a palavra "não" e fica intrigada quando se vê no espelho. Vê o pai descascando uma banana e não se contenta em recebê-la descascada pela metade. Termina de fazer o resto.

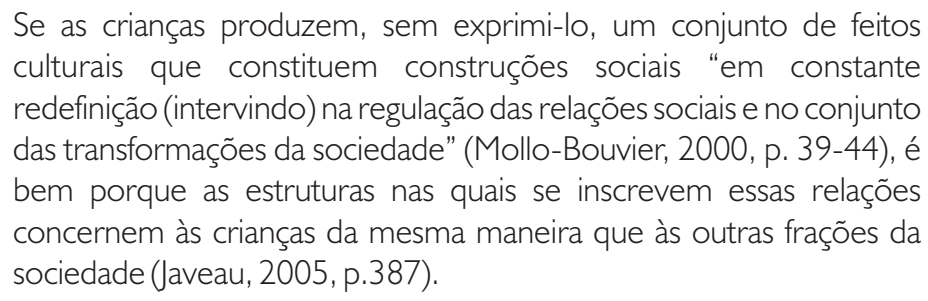
das transformações da sociedade" (Mollo-Bouvier, 2000, p. 39-44), é bem porque as estruturas nas quais se inscrevem essas relações concernem às crianças da mesma maneira que às outras frações da sociedade (Javeau, 2005, p.387).

A personagem talvez seja a mais notória do filme, se partirmos do princípio de que a cultura norte americana é tão disseminada, principalmente pela mídia, que parece já fazer parte do nosso cotidiano. Hattie evidencia indícios de uma autonomia quando parece "copiar" os adultos ou arranjar "soluções" para suas atividades do dia-a-dia, como fugir e negar as imposições de seus pais. Ela é mesmo um ser em transformação, já destacado por CARVALHO (2010), que influencia e é influenciada pelas transformações da sociedade. 
Nascida no Japão, Mari é filha única e mora com seus pais em Shibuya, uma área metropolitana de Tóquio. Vai para uma espécie de creche onde todos os bebês choram. Enquanto engatinha quer conhecer as coisas, papel, cd, computador. Quando aprende a andar, caminha pelo centro da cidade. Tem medo do tigre do zoológico e tenta colar adesivos no desenho que fez.

O aspecto fundamental da participação de Mari no filme representa aquilo que Corsaro (2009) explica através da reprodução interpretativa:

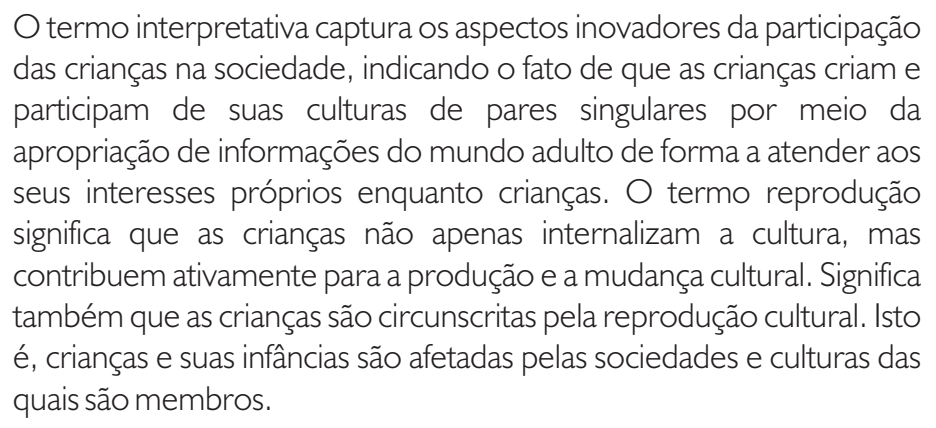

Mesmo a afirmação podendo caber a todos os bebês do filme, inclusive aos irmãos dos que os possuem, Mari chama a atenção para uma cena em especial: como ela observa sua mãe diariamente se vestir, tenta fazer igual enquanto está sentada à mesa com seu babador. Sem sucesso, tenta de outras maneiras, depositando-o simplesmente em cima da cabeça. Sabendo que esta não é a forma certa, acaba chorando.

A mesma situação é vivida por Hattie, ao descascar a banana. A este respeito Corsaro afirma: "A produção da cultura de pares pelas crianças não é uma questão de simples imitação. As crianças apreendem criativamente informações do mundo adulto para produzir suas culturas próprias e singulares" (2009, p. 32).

\section{Considerações finais}

"Babies" retrata a vida da família comum em diferentes culturas, durante o nascimento de quatro bebês. Nele, podemos perceber que apesar da diversidade cultural, muitas características são comuns. $\mathrm{O}$ filme nos remete a viver cada uma das pequenas histórias cotidianas como se fossem nossas, já que os ângulos em que as câmeras foram dispostas permitem que todos os personagens sejam notados em sua vivência real.

Todas as etapas são contempladas: a gravidez, registrada com aparelhos nas áreas urbanas e de modo natural nas áreas rurais; a amamentação, registrada de maneira "grosseira" quando a mãe 
tem que dividir um seio para cada filho em Namíbia, ou quando a mãe joga seu leite no rosto do bebê na Mongólia; o banho, registrado no chuveiro no colo do pai, nos Estados Unidos, e através de lambidas da mãe em Namíbia; a relação com os animais, registrada na Mongólia com o bebê brincando sozinho e pelado no meio de bois e cabritos, e no Japão, com o bebê dormindo na mesma cama que o gato; e o andar, registrado em Namíbia com o bebê já carregando uma lata na cabeça, e no Japão, quando o bebê brinca em um labirinto no parque.

O filme expressa o cotidiano destes bebês, no qual, cada um, sob suas condições, experimenta conhecer o mundo à sua volta, os objetos e os animais - que parecem não oferecer perigo. É um retrato da infância de múltiplas nacionalidades, no qual a diversidade cultural faz parte da narrativa, demonstrando estímulos e hábitos de infâncias tão comuns, mas tão diferentes. Mesmo em culturas quase que extremas, todos os bebês demonstram emoções, todos passam pelas mesmas etapas de desenvolvimento e ao mesmo tempo, os pais parecem ter diferentes modos de lidar com os mesmos problemas, além dos espaços da narrativa - rural e urbano - implicarem em modos de socialização diferentes.

Uma aula de observação de crianças, "Babies" revela que para a pesquisa sobre a infância é preciso observar os sujeitos da maneira mais real possível, com um olhar atento e aguçado, levando em consideração o seu contexto e a cultura à qual o indivíduo foi submetido a se desenvolver, de maneira a atribuir mais sentido aos resultados. Observar o que os bebês "fazem" remete a vislumbrar o que eles "são" e assim, compreendê-los como indivíduos sujeitos de uma história. 
Referências

BALMÈS, Thomas; CHABAT, Alain. Bébé(s). França, 2010. Disponível em: http://focusfeatures.com/babies. Acesso em 8 de outubro de 2013.

CAMPOS, M. M. Por que é importante ouvir a criança? A participação das crianças pequenas na pesquisa científica. In: CRUZ, S. H. V. A criança fala. A escuta de crianças em pesquisas. São Paulo: Cortez. 2008.

CARVALHO, M. J. L. Trajectos de vida, o outro lado da cidade: pobreza infantil, território e desvio. In: SARMENTO, M. J., VEIGA, F. (org.) A pobreza infantil. Realidades, desafios, propostas. Apartado: Húmus. 2010.

CASTELLI, Carolina Machado; MOTA, Maria Renata Alonso. A complexidade de ser bebê: reflexões acerca de sua visibilidade nas creches e nas pesquisas. Revista Zero-a-Seis, $\mathrm{n}^{\circ}$. 28, p. 46-65, UFSC, 2013. Disponível em: https://periodicos.ufsc.br/index.php/zeroseis/article/view/28013. Acesso em 14 de outubro de 2013.

CHRISTENSEN, P.; JAMES, A. Pesquisando as crianças e a Infância: culturas de comunicação. In: CHRISTENSEN, P.; ALLISON, J. Investigando com crianças: perspectivas e práticas. Porto: Escola Superior de Paula Franssinetti. 2005.

CORSARO, W. A. Reprodução interpretativa e cultura de pares. In: MULLER, F.; CARVALHO, A. M. A. Teoria e prática na pesquisa com crianças. Diálogos com William Corsaro. São Paulo: Cortez. 2009.

JAVEAU, C. Criança, infância(s), crianças: que objetivo dar a uma ciência social da infância? Educ. Soc., Campinas, vol. 26, n. 91, p. 379-389, Maio/Ago. 2005.

KOHAN, W. O. A infância escolarizada dos modernos. In: KOHAN, W. O. Infância: Entre educação e filosofia. Belo Horizonte: Autêntica. 2003.

LIMA, Patrícia de Moraes; NAZÁRIO, Roseli; SCHMITT, Rosineti Valdeci. A infância pelas lentes do cinema. XXIII Ciclo de Debates sobre Educação Infantil. Revista Zero-a-Seis, n ${ }^{\circ} .28$, p. 91-95, UFSC, 2013. Disponível em: https://periodicos.ufsc.br/index.php/zeroseis/article/view/29921. Acesso em 14 de outubro de 2013.

SARMENTO, M. J. As Culturas da Infância nas encruzilhadas da $2^{\mathrm{a}}$ modernidade. In: M. J. Sarmento, e A. B. Cerisara, (coord), Crianças e Miúdos. Perspectivas sociopedagógicas sobre infância e educação. Porto. Asa. (9-34). 2004. 